\title{
LA VOZ DE LOS MORISCOS EN LOS LAR DEL REINO DE GRANADA (Deslindes y amojonamientos)
}

\author{
Juan Abellán Pérez*
}

Aunque buena parte de los $L A R$ del reino de Granada ya han sido objeto de estudio ${ }^{1}$, siguen siendo una importante fuente de información sobre la comunidad musulmana antes y después de su conversión forzosa al Cristianismo; de la compleja y ordenada estructura que presentan estas fuentes se ha destacado fundamentalmente los aspectos socio-económicos y, en menos medida, otros; sin embargo, en estos textos documentales subyace otro tipo de información que no falta a simple vista y que viene a ser la voz callada de esa comunidad que, muy veladamente, aprovecha su participación en algunas algunas de las fases de la confección de estos libros como la fijación de los deslindes y amojonamientos, cuantificación de los bienes muebles e inmubles del municipio y en la propiedad de los mismos para transmitir, aunque parcialmente, sus modos de vida y cultura.

De todos los apartados que ofrecen los $L A R$ nos centramos en los deslindes y amojonamientos ${ }^{2}$, pero, como es natural, la diversidad geográfica del antiguo reino de Granada y los pasos que sigue la población musulmana hasta su conversión y de ésta a su expulsión en el siglo XVI, nos obliga, en este planteamiento metodológico, a hacer una selección de las fuentes.

\section{LA VOZ DE LOS MORISCOS EN LOS LAR}

En líneas generales, en una serie de lecturas minuciosas de estos textos, sin ponderar en exceso la abundancia de datos, se puede observar con cierta

\footnotetext{
* Universidad de Cádiz.

1. Una amplia recopilación de la bibliografía sobre los moriscos granadinos puede verse en Barrios Aguilera, M. y Birriel SAlcedo, M.: La repoblación del Reino de Granada después de la expulsión de los moriscos. Fuentes y bibliografía. Estado de la cuestión, Granada, 1986.

2. Los Libros de Apeos y Repartimiento que manejamos se encuentran en el Archivo de la Real Chancillería de Granada.
} 
claridad que los nuevos cristianos fueron un eslabón más del largo proceso cultural andalusí que retomando la mixtura de su pasado histórico supieron transmitirlo con voz propia, haciendo posible que aquella estuviera presente aun despues de su expulsión, e, incluso, en la actualidad.

Ese papel de puente que ejercen los moriscos entre la Edad Media y la Modernidad abarca un amplio abanico que, sin lugar a dudas, adquiere mayor relevancia en la descripción del paisaje urbano y rural, en la flora y fauna, en las vías de comunicación y en sus modos de vida, y, todo ello, es posible encontrarlo en la toponimia.

Es incomprensible, a primera vista, que tras el fuerte proceso de cristianización que se sigue con los mudéjares granadinos, con la intención de borrar sus costumbres y religión, se permitiera a los moriscos, durante los setenta años que transcurrieron desde la conversión a la expulsión, mantener tan alto porcentaje de vocablos arábigos que, por otro lado, le evocaban diariamente el principal vehículo de su cultura, la lengua; sin embargo, la implantación de las estructuras de poder castellano, tras la caída de Granada, al no prever la Corona la expulsión de la población musulmana, ésta siguió siendo mayoritaria, sobre todo en el medio rural y, por tanto, la escasa presencia de cristianos viejos en los municipios no alteró sustancialmente el desarrollo de la vida ni las variantes que se introdujeron por parte de la nueva administración fueron lo suficientemente fuertes como para hacer desaparecer totalmente los signos culturales.

Los moriscos del reino de Granada sigueron utilizando su lengua materna, el árabe o algarabía, como vehículo de comunicación, aunque por asimilación hubieran incorporado, desde antiguo, voces romances. Ello no implica el hecho de que algunos moriscos tuvieran conocimiento de la aljamía, e incluso que llegaran a expresarse en esta lengua con cierta fluidez, pero su número fue tan escaso que no permite hablar de bilingüismo, justificando, en consecuencia, la proliferación de intérpretes.

Una prueba de esta afirmación la encontramos en los textos que manejamos, donde se puede observar que cuando se hace referencia a los mojones, éstos se designan con el nombre arábigo seguido de su traducción en aljamía, y muy pocas veces a la inversa; entre otros ejemplos citamos los siguientes.

En el valle del río Almanzora:

Villa de Fines ${ }^{3}$ :

“... un mojon antiguo que se dize Aynçayd que quiere dezir en aljamia la Fuente del Concejo ...".

“.. hasta dar a una peña que se dize el Hafacatra que en aljamia quiere deçir la Peña Amarilla ...".

3. El deslinde y amojonamiento se realizó en 1572. 
"... a un mojon que estaba hecho de cal y canto que se dice Ay o quer albacar que en castellano quiere deçir adonde mataron las vacas ... “.

"... hasta un çerro que es blanco y colorado y tiene enmedio una çinta de yerba que se dieze riquiv maçil Gonçales Senesi ...".

Villa de Macael ${ }^{4}$ :

"El primero mojon es en el pago de Cafornal que se llama Andaalcho ${ }^{5}$ en arabigo que en nuestro vulgar quiere dezir el barranco de la anbre ...".

"... de alli a otro mojon que llaman Cahalocta ${ }^{6}$ quiere dezir en nuestro vulgar nudo de olivos ...".

"... y de alli a Fedialcolat ${ }^{7}$ que quiere dezir el çerro de Alcantara ...".

“... y este lugar asta el mojon que dizen el çerro aspero que en arabigo dize Fechet Alarafa ${ }^{8}$...".

“... y de alli va al mojon que dizen de Quit que en nuestro vulgar se dize el Gato ...".

"... que se dize Andad Alebje 9 que quiere dezir el barranco del Almendro ...".

"... e de alli va otro mojon que dizen Cudiat Acytil que quiere dezir el cerro de la fuente del Til ...".

“... y de alli va otro mojon que se dize Faz Habempides ${ }^{10}$ que quiere dezir el campo de Benpides ...".

"... y de alli va otro mojon por la dereçera que dizen Cudiat Alforca que quiere dezir en nuestro vulgar el cerro de la Orca ...".

"... y de alli va a otro mojon que dizen el Maxihet que es en bulgar el Bojar ...".

"... va a un mojon que dizen de la Aurica que dizen de la Ygera ${ }^{11}$...".

"... y de alli a otro mojon que dizen Andaca Alnachat ${ }^{12}$ que dizen el barranco del Carpintero ...".

"... y de alli a otro mojon por el dicho termino de Gemeçil que se llama el Maguivet ${ }^{13}$ que quiere dezir el mojon del Colmenar ...".

"... en la mano aparar a una era que en arabigo dizen Fechiabulli ${ }^{14}$...".

4. El deslinde y amojonamiento se hizo en 1573 .

5. Sobre este deslinde y amojonamiento existen dos copias de la misma fecha, pudiéndose observar en su comparación diferencias en las grafías. En el segundo texto se lee el topónimo: Handac Alcho.

6. En el segundo texto, Calahota.

7. En el segundo texto, Fedialcolad.

8. En el segundo texto, Feched Alaraja.

9. En el segundo texto, Andat Alebje.

10. En el segundo texto, Faça Venpides.

11. En el segundo texto, Yguera.

12. En el segundo texto, Andacahalnahat.

13. En el segundo texto, Magibet.

14. En el segundo texto, Fechet Abullei. 
En la villa de Alfacar ${ }^{15}$ :

"... hasta el rio de Handacadub, que en lengua castellana quiere dezir el barranco del Oso ...".

"... una fuente que se dize Aynealmuçur, fuente de las Aguilas, en aljamia ...".

"... hasta dar en la queba del Agua, que se dize en algarabia Algaralmudfum ...".

"... que tiene una piedra enhiesta, que se dize en algarabia Alguaquif ...".

"... por una cañada abaxo hasta dar a el puerto que se dize algarabia Alhalc ...".

En la serranía de Ronda ${ }^{16}$ :

"... e dexando la que los christianos dizen Mazmorilla e los moros Almadrava, que es un tejar ...".

"... en un çerro que se llama de Escudilla y en lengua araviga se dize Çafra ...".

"... un arroyo que se llama de las Piletas que se llana Handalgoçan ...".

"... sobre un lomo que se dize Arramal, que dixeron que dizen en romançe el campo de la Arena ...".

En estas relaciones toponímicas podemos observar la relacion árabecastellano, árabe-romance, árabe-aljamía y árabe-vulgar o algarabía-castellano y algarabía-aljamía; sin embargo, ello no quiere decir que la población que habitaba en los lugares sobre los que se basan nuestras fuentes lo fuera, como bien apunta el Dr. M. de Epalza ${ }^{17}$ : "La castellanización de esa gran masa demográfica de árabehablantes no pudo ser rápida y a mediados del siglo XVI eran muchos los que ignoraban totalmente el castellano, especialmente en las zonas rurales".

Este dualismo, generalmente, se inicia con el término árabe seguido de la traducción en castellano, lo que viene a afianzar el monolingüismo de la zona; no obstante, los textos no recogen la traducción de la totalidad de los topónimos árabes como Hofar, Mizra, Pontoji o Pontoxi, Azhab, Hizbala, Atalaya, Fechet Almaguara, Algodayarit, Hayabulbada, Bontir, Pidauque, Fechiabulli, Fechetairula, Bayde, Mocruyle, Cafornal, Tamayrul, Nautar, Escopón, Atucha, etc.; esta abundancia de vocablos arábigos acentúa la afirmación anterior.

15. Barrios Agulera, M.: Alfacar morisco. Un lugar de la Vega de Granada en el siglo XVI, Granada, 1984, pp. 142-147. El estudio de estos topónimos de Alfacar puede verse en DíAz GARCía, A. y BARRIOS Aguilera, M.: De toponimia granadina. Un estudio histórico-lingüístico según el Libro de Apeo y repartimiento de Alfacar, Granada,1991.

16. Abellán Pérez, Juan: «La toponimia hispano-musulmana de la serranía de Ronda según los deslindes entre Ronda, Montejaque y Benaoján», en Homenaje al Dr. D. Jacinto Bosch Vilá, Granada, 1991, II, pp. 837-846.

17. EPALZA, Míkel de: Los moriscos antes y después de la expulsión, Madrid, 1992, pp. 116-117. 
Las deportaciones que siguieron a la guerra de Las Alpujarras dejaron en el reino de Granada un vacío poblacional, más acuciante en el medio rural, donde la paralización de la vida hasta el nuevo poblamiento cristiano dejó plasmada en el paisaje la voz monolingüística de los moriscos, la parte visible de una cultura cuyas raíces, en mayor o menor medida, según las zonas, se pueden rastrear en la documentación.

Ese monolingüismo es el que determinó que, a la hora de declarar los términos antiguos de las localidades, se designaran generalmente a moriscos bilingües, aunque el control que tenían de la nueva lengua no fuera, en algunos casos, completo, puesto que, como se atestigua en la villa de Fines, Diego Garcia Abençorayque, de 30 años, no sabía escribir en castellano; exactamente ocurre en Alfacar donde Diego el Xerrí -52 años-, Bartolomé Abencalaf -30 años-, Benito -67 años- y Francisco Alalux -34 años-, seises moriscos, eran analfabetos ${ }^{18}$, y aunque no tenemos certeza, lo mismo debió ocurrir en Macael, donde fueron nombrados como apeadores un cristiano viejo, Juan Román, beneficiado, en calidad de persona antigua del lugar y el morisco Lorenzo Zanbra.

Resumiendo, en el medio rural granadino, los moriscos, en su vida cotidiana, se expresan en lengua propia, el árabe dialectal andalusí, impregnando el espacio geográfico donde habitan; con el paso de los siglos, a través de la toponimia y de otros tipo de fuentes escritas, se ha conservado viva, aunque en silencio, la voz de esa comunidad, siguiendo, en la actualidad, despertando el interés de la investigación por profundizar en algunos temas y sacar a la luz nuevas facetas.

\section{APÉNDICE DOCUMENTAL}

Deslinde y amojonamiento de la villa de Fines (1572).

Primeramente se fue a un mojon antiguo que se dize Aynçayd que quiere deçir en aljamia la fuente del Concejo, en que ay un almez que tiene una cruz, el qual quedo por mojon y divide los terminos de Purchena y Oria y Fines, quedando el termino de Fines a mano yzquierda y los demas a mano derecha. Siendo testigos los dichos conoçedores y Xorge Gil, alcayde y gobernador de la dicha villa.

18. Barrios Aguilera, M.: op. cit., p. 24, nota 22. 
E luego, yncontinente, rebolbiendo sobre mano yzquierda se fue por la rambla derecho hacia el medio hasta dar en el pago que dizen el Hofar, donde esta hecho un mojon de piedras, el qual divide los terminos de Fines y Olula, quedando el de Fines a mano yzquierda y el de Olula a mano derecha. Testigos los dichos.

E luego, yncontinente, rebolbiendo sobre mano yzquierda se fue derecho hazia el mediodia hasta dar a un lentisco grande donde se hallo un mojon de piedras antiguo, el qual divide los dichos terminos de Fines y Olula, quedando como dicho es, el de Fines a mano yzquierda y el de Olula a mano derecha. Testigos los dichos.

El luego, se fue derecho hazia el mediodia hasta dar a un mojon que estaba hecho de cal y canto que esta junto a el camino real, que se dize el mojon del Serbal, el qual quedo por guia.

$Y$ luego, se fue derecho haçia el mediodia, pasando el rio que dizen de Almançora, hasta dar a otro mojon que estaba hecho de cal y canto, que estaba en un çerrillo que dizen del Mizra, el qual divide los dichos terminos de Fines y Olula, quedando el de Fines a mano yzquierda y el de Olula a mano derecha. Testigos los dichos.

Y luego, yncontinente, rebolbiendo sobre mano yzquierda se fue derecho haçia el mediodia hasta dar a otro mojon que estaba hecho de cal y canto, que esta enzima de una peña que se el Arjon, el qual quedo por guia.

$Y$ luego, yncontinentye, se fue derecho haçia el mediodia hasta dar a otro mojon que estaba hecho de cal y canto, que se dize el Pontoji, el qual divide los terminos de Macael y Olula y Fines, quedando el de Fines a mano yzquierda y los demas a mano derecha. Testigos los dichos.

Y luego, dende alli, rebolbiendo sobre mano yzquierda se fue derecho haçia el Levante hasta dar a un mojon de piedras antiguo que se dizen las casas de Benali, el qual quedo por guia.

Y luego, dende alli, se fue derecho hazia el Levante hasta dar a una peña que se dize el Hafaçatra que en aljamia quiere deçir la peña Amarilla, la qual quedo por guia.

E luego, dende alli, se fue derecho hazia Levante hasta dar en el pago del Azhab, en el qual esta hecho un mojon de piedras junto a un secano que hera de Garçia el Marabayte, morisco, vezino de Fines, el qual quedo por guia.

E luego, dende alli, se fue derecho hazia el Levante hasta dar a un mojon que estaba hecho de cal y canto, que se dize Ay aquer albacar que en castellano quiere deçir adonde mataron las vacas, el qual divide los terminos de Lijar y Cantoria y Fines, quedando el de Fines a mano yzquierda y los demas comarcanos a mano derecha. Siendo testigos los dichos.

$Y$ luego, yncontinenete, revolbiendo sobre mano yzquierda se fue hazia el Norte hasta dar a unos pinos que estan enzima de un barranco hondo que se dize el barranco del Escopon, los quales quedaron por Guia. Siendo testigos Jorge Gil y Francisco Sanchez y Francisco de Tortosa, estantes en el dicho termino.

Y luego, yncontinente, se fue dende la dicha guia derecho hazia el Norte, pasando el dicho barranco hasta dar a un çerrillo alto de Atucha, junto a un puerto de zorzales de Diego Alabiat, veçimo de Fines, el qual dicho çerrillo quedo por guia.

Y luego, yncontinente, se fue derecho hazia el Norte, atravesando una cañada de Diego Alabiat, morisco, vezino de Fines, hasta dar a una higuera que esta junto al rio que dizen de Almanzora, nascida en una peña que dizen Hizbala, la qual quedo por mojon y divide los terminos de Cantoria y Fines, quedando el de Cantoria a mano derecha y el de Fines a mano yzquierda. Testigos los dichos.

Y luego, yncontienente, rebolbiendo sobre mano derecha, se fue dende el dicho mojon de la higuera por el rio abajo hasta dar a una rambla grande que viene a dar a el 
dicho rio por detras de la Atalaya, a donde esta un olivo enzima y en junta de la dicha rambla y rio, el qual dicho olivo quedo por mojon, y en el se hizo una cruz, el qual divide los terminos de Cantoria y Fines, quedando el de Cantoria a mano derecha y el de Fines a mano yzquierda. Siendo testigos los dichos.

... e luego, yncontinente, revolbiendo sobre mano yzquierda y dejando la dicha rambla, se fue derecho hazia el Norte, y andando hasta un tiro de piedras se hizo una guia de piedras enzima de otras que estaban puestas por señal antiguamente, junto al camino que ba de Fines a Partaloba.

$\mathrm{Y}$ luego, yncontinente, rebolbiendo sobre mano yzquierda y dexando el dicho camino a mano derecha se fue hazia el Norte por una loma arriba, dexando aguas vertientes a los dichos terminos de Fines y Cantoria, hasta un çerro que es blanco y colorado, y tiene enmedio una çinta de yerba que se dize Riquiv Maçil Gonçales Senesi, el qual quedo por mojon y divide los terminos de Partaloba y Fines, quedando el de Fines a mano yzquierda y el de Partaloba a mano derecha.

$Y$ luego, yncontinente, rebolbiendo sobre mano yzquierda se fue derecho a el Poniente, la falda de la sierra adelante junto a los pinos de los çerros altos hasta dar a el primero mojon que se dizo a el prinicpio del dicho amojonamiento que se dize Aynçayd con el qual se concluyo el dicho amojonamiento. Siendo testigos los dichos.

2)

\section{Deslinde y amojonamiento de la villa de Macael (1573).}

La qual es en esta forma:

Que parte terminos con la ciudad de Purchena por los mojones siguientes: El primero mojon es en el pago de Cafornal que se llama Andaalcho en arabigo, que en nuestro vulgar quiere dezir el barranco de la Anbre, e del dicho mojon va a otro que llaman de la Caça que abra un quarto de legua, y este mojon parte terminos entre la dicha çiudad de Purchena y la villa de Olula que es de don Andres Serrano, que es padron de todos tres terminos, y este mojon es de argamasa, y del dicho mojon va por el termino de Olula y de Macael.

La mojonera que es primero mojon es el barranco de Lijar que abra de uno a otro un tiro de arcabuz, e de dicho mojon a otro que llaman Fechet Almaguara que es ansi mismo de argamasa, e de alli a otro mojon que llaman Cahalota que quiere dezir en nuestro vulgar Nudo de Olivos que esta cerca el uno de otro, y del dicho mojon la derecera en la mano asta dar al çerro Quebrantahuesos, y de alli a Fedialcolat que quiere dezir el cerro de Alcantara, e de alli otro mojon al çerro de Pontoxi que es padron entre el termino de Olula y Fines ques de Galago Rotuli (sic) y de Macael, y del dicho mojon va la mojonera entre el termino de Fines y este lugar asta el mojon que dizen el çerro Aspero que en arabigo dize Fechet Alarafa y queda enmedio el mojon que dizen del Candelero, y de alli va al mojon que dizen de Quit que en nuestro vulgar se dize el Gato, y del dicho mojon va al mojon de la cueva de la Paja, y de alli va Algodayarit ques en el rio del Gat, e del dicho mojon va a otro mojon ques padron entre la villa de Lijar ques de don Alonso Carrillo y este lugar y el de Fines que se llama Andad Alebje que quiere dezir el barranco del Almendro ques mojonera entre la dicha villa de Macael e Lijar, e de alli va otro mojon que dizen Cudiat Ayntil que quiere dezir el çerro de la fuente del Til, y de alli va otro mojon que se dize Faz Habempides que quiere dezir el campo de Benpides, que es do esta una balsa do bebe el ganado, y de alli va otro mojon por la derecera que dizen Cudiat Alforca que quiere dezir en nuestro vulgar el çerro de la Orca, y de alli va a otro mojon que dizen el Maxihet que es en vulgar el Bojar, y este mojon es padron entre la dicha villa de Lijar y la villa de Chercos 
ques en la sierra de Filabres y es de don Enrrique de Guzman, y de alli va a un mojon que dizen de la Aurica que dizen de la Ygera, y de alli a otro mojon que dizen Andaca Alnachat que dizen el barranco del carpintero, y de alli a otro mojon que dizen Hayabulbada que es en una hera, y este es padron entre Chercos y Jemeçil, ques del dicho don Enrrique heste lugar, y de alli a otro mojon que va al corral de Lahanquez, vezino que era de Jemeçil, y de alli a otro mojon por el dicho termino de Gemeçil que se llama el Maguivet que quiere dezir el mojon del Colmenar, el qual es padron entre Gemeçil e Benitarafat que es del dicho don Enrrique, y de alli la derecera en la mano a otro mojon que se llama el Bontir que parte termino con Benitarafat, y de alli a otro mojon que dizen el Pidauque, que este es padron entre este lugar y Benitarafat y Alaroya que es jurisdiçion de Baça, e desde aqui comença el termino de Alaroya que se va amojonando e deslindando en esta manera:

La desmeria de anbos lugares, puesto que anbos son jurisdiçion de Baça y se incluyen en la dicha jurisdiçion que desde el mojon del Pidaupe que esta dicho va la derecera en la mano aparar a una era que en arabigo dizen fechiabulli, y de alli va la cordillera en la mano aguas vertientes contra Macael y Alaroya por el çerro de la Bayde y va a dar a otra era que se llama Fechetairula, y de alli otro mojon que es en el corral de Lope de Antequera, vezino que era de Halaroya, que es en el pago de Tamayrul, y de alli al çerro que dizen del Mocruyle y de alli al barranco de Nautar, y de alli va otro mojon al barranco Hondo, y de alli al mojon de Andacachos que es el primero mojon por do esta mojonera se començo en el prinzipio della. 